\title{
Total Cost of Ownership Considerations in Global Sourcing Processes
}

\author{
Robert Alard, Philipp Bremen, Josef Oehmen, and Christian Schneider \\ ETH Center for Enterprise Sciences (BWI), Department of Management, Technology, and \\ Economics, ETH Zurich, Zurich, Switzerland \\ ralardaethz.ch
}

\begin{abstract}
Even within the financial crisis Global Sourcing is gaining more and more importance. Although a lot of European companies have already a long experience with international supply markets, uncertainties about the consequences and the costs related to a specific international supplier selection still remain. The Total Cost of Ownership concept is an interesting approach in order to cope with this problem. In the present paper key requirements for a Total Cost of Ownership concept from an industrial perspective are described. In the following, a Total Cost of Ownership concept is presented which allows conducting detailed Total Cost of Ownership calculations structured in different key modules. These key modules base on macroeconomic and microeconomic aspects which can also be largely used independently.
\end{abstract}

Keywords: Global Supply Networks, Total Cost of Ownership, Global Total Cost of Ownership, Global Procurement, Outsourcing, Supplier Evaluation, Country Assessment.

\section{Global Sourcing}

Global Sourcing is gaining more and more importance. For many European companies East European and Asian supply markets are promising alternatives to local sources. The key reasons for Global Sourcing initiatives from a European perspective are a) cost reductions, b) market access considerations (e.g. access through a supplier to promising sales markets, regional knowledge), c) technological requirements (e.g. some supplier or technology cluster can only be found in some supply markets) d) the proximity to customers (e.g. to follow a key customer into these markets) or e) legal issues (e.g. need for local content, tax issues, subsidies, certificates). Nevertheless Global Sourcing is - from a procurement perspective - a challenging topic with serious pitfalls for the customer. So it is essential to adapt the procurement processes for Global Sourcing activities and implement important global aspects ex-ante. Figure 1 describes an enhanced strategic process model including relevant considerations related to international procurement initiatives.

An interesting approach within this context is the Total Cost of Ownership (TCO) model which can be defined as an estimation of all direct and indirect costs associated with a specific procurement object over its entire life cycle. An integral 
TCO approach is of big support for the Make-or-Buy decision and the supplier evaluation (ex-ante) as well for the supplier development and supplier controlling in the operative procurement (ex-post). Even if TCO is a well-known term in the scientific community and some approaches have been developed (see [2, 3, 4, 5, 6, 7, and 8]), no viable integral models are known for Global Sourcing procurement activities which are in use in daily business. An analysis conducted with 24 Swiss industrial companies in two research projects (see $[9,10])$ showed that from procurement perspective no full TCO approach is available in industrial practice. In some cases calculations or estimations for specific cost blocks are used (e.g. transports costs, quality costs) with strong limitations of the scope. For example the calculations are only focused on specific procurement object groups, e.g. the internal procurement from an international subsidiary. Especially long-term implications of Global Sourcing activities are often not considered in a systematic way or even calculated. For example long transport lead times caused by container shipping from Asian suppliers to the customer's reception point (e.g. warehouse in Europe) lead to a loss of flexibility and high safety stocks for the European buyer, both factors which should be seriously considered and calculated when setting up a global supply network. A critical issue from an industrial perspective regarding the use of the existing TCO concepts seems to be the high complexity and the mostly theoretical background of existing models. Most of the industrial partners accentuate the easy-to-use, adaptive and comprehensible character of a modern TCO concept in order to fulfill their daily needs and requirements (see chapter 4 ).

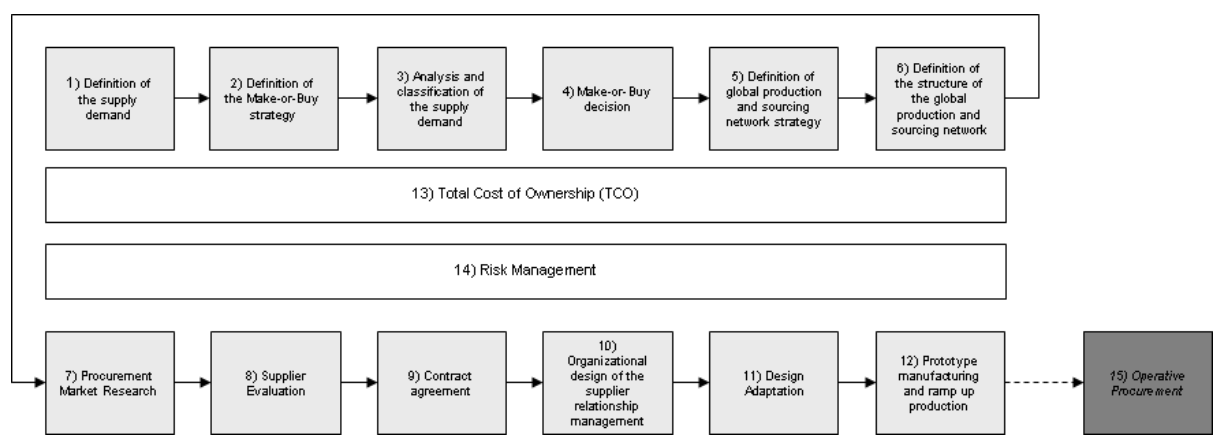

Fig. 1. Global Sourcing process and its steps (strategic procurement perspective) (adapted from [1])

\section{Objectives of the TCO Concept}

The objective of this paper is to describe an integral TCO concept focusing on Global Sourcing projects for the mechanical engineering industry. This concept covers amongst others relevant strategic and operative procurement processes and cost drivers in a quantitative and qualitative way and should be applicable for small- and mediumsized companies as well for mid-sized companies. The life cycle cost examination for this TCO concept is - according to complexity limitations and practical requirements bordered to the phases from contract agreement (strategic procurement) up to goods 
receiving / quality control (operative procurement) at the customer's site or up to the delivery on the construction site for plant construction business (until the final customer acceptance procedure has been completed). Further aspects like for example operating costs, maintenance costs or recycling costs of the procurement object are not focus of this TCO concept - the Life Cycle Cost approach is hence limited to a procurement perspective. The described TCO concept will enable the management, the procurement and logistics specialists to conduct a holistic supplier evaluation (ex-ante) (e.g. comparing different supplier alternatives in different countries), to perform make-or-buy decisions as well as supporting the supplier development and supplier controlling (expost) including macroeconomic aspects. Figure 2 shows the different potential applications (and outputs) of the TCO concept.

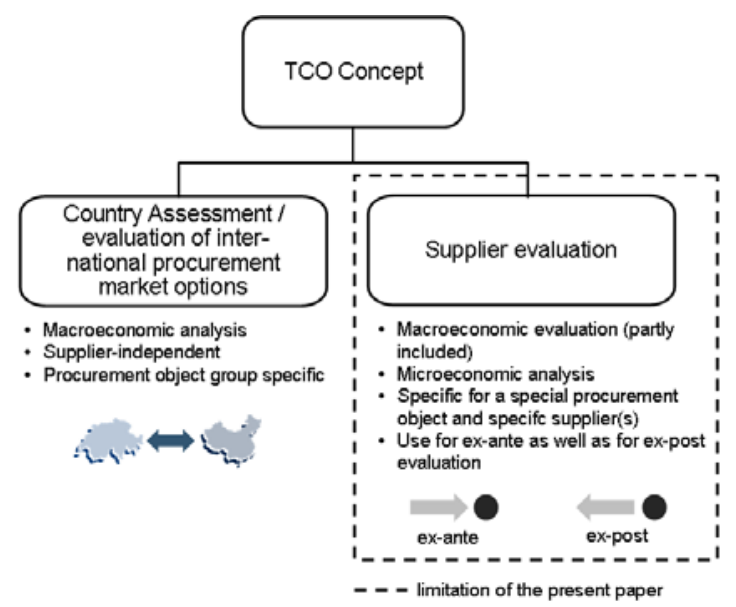

Fig. 2. TCO Concept and use of the concept in different context

Besides the supplier evaluation from a holistic perspective (ex-ante as well as expost) a country assessment can be performed, based on macroeconomic indicators and export statistics (see left side of figure 2). Country assessments describe the evaluation of international procurement markets for a specific procurement object group. For example it could be interesting to know which procurement markets are most promising to search for suppliers specialized on specific procurement object groups (e.g. solar equipment or printed circuit boards). The topic of the country assessment (left part of figure 2) will not be described further in this paper. A general procedure of this top-level supplier market analysis based on macroeconomic data and export statistic ratios can be found in [11].

\section{Research Method}

The research method used to develop the TCO concept followed the problem solving cycle of the Systems Engineering (SE) method [12]. The first phase of SE can be subdivided into situation analysis (system delimitation, strengths and weaknesses analysis, opportunities and threats analysis) and goal definition, the second phase into 
concept synthesis and concept analysis, and the third into evaluation, decision and implementation. Within the concept synthesis innovations are developed to address the given constraints either through creation of alternative concepts or also through deductions from the existing literature [13].

This general approach was combined with the more specific case study research method. To obtain the results, holistic multiple case studies were conducted (19 general case studies, 5 detail case studies). The detail case studies were conducted in Swiss mechanical engineering industry (three make-to-stock companies, two plant construction companies). In order to reach a broad usability of the TCO tool in the future, companies of different sizes were included in the detail case studies / analyses, e.g. two large companies and three small-to-medium sized companies.

\section{Requirements for a TCO Tool}

As part of the situation analysis and objective formulation several half-day and whole-time workshops have been performed with industrial partners. These workshops were individual workshops and partly workshops in a consortium group, the average time used for each company was there days. Key objective of the first workshops was the identification of the requirements for a TCO concept. Figure 3 shows an excerpt of the consolidated objectives from an industrial perspective (excerpt).

\begin{tabular}{|l|l|l|l|}
\hline Class & Sub-class & Objective & Priority \\
\hline Functionality & $\begin{array}{l}\text { Objective } \\
\text { of tool }\end{array}$ & $\begin{array}{l}\text { Evaluation of different supply options / suppliers in } \\
\text { the local and global context }\end{array}$ & Must \\
\hline Functionality & $\begin{array}{l}\text { Objective } \\
\text { of tool }\end{array}$ & $\begin{array}{l}\text { Utilization of the TCO tool for ex-ante and ex-post } \\
\text { calculations }\end{array}$ & Must \\
\hline Functionality & $\begin{array}{l}\text { Objective } \\
\text { of tool }\end{array}$ & Analysis of the cost structure of a supplier (RFQ) & $\begin{array}{l}\text { Nice to } \\
\text { have }\end{array}$ \\
\hline Functionality & $\begin{array}{l}\text { Cost } \\
\text { elements }\end{array}$ & $\begin{array}{l}\text { Structuring of the cost elements into modules } \\
\text { (should be as independent as possible) }\end{array}$ & Must \\
\hline Functionality & $\begin{array}{l}\text { Cost } \\
\text { elements }\end{array}$ & $\begin{array}{l}\text { Consideration of dynamic changes of input data } \\
\text { (e.g. currency exchange rates) }\end{array}$ & Must \\
\hline
\end{tabular}

Fig. 3. Example of some consolidated objectives for a TCO concept / TCO tool from an industrial perspective (excerpt)

Some of these objectives are described in the following. Generally the tool should be able to consider and evaluate different supply options / suppliers in the local and global context (e.g. comparison of an existing supplier in Europe with a new supplier in China). An important point for the TCO tool will be the inclusion of dynamic factors, e.g. the fluctuations of currency rates or transport costs. These issues can be seen as critical limits included in the TCO tool, e.g. if the exchange rate of RMB/€ reaches a certain level a specific supply situation may not be worthwhile anymore, or in the opposite sense, a supply option may be revaluated again if the currency exchanges develops in favor for the customer. A data set of macroeconomic parameters for a specific country should be accordingly provided periodically, so it is important to find 
a procedure to update this data set in regular time intervals (e.g. labor cost, skill base, research and developments capacity, currency rates, inflation). Specialized providers of such macroeconomic data are available, see for example [14]. One important requirement for the TCO concept / tool is the IT-support. Following the potential industrial user needs, the TCO tool should be based on standard IT tools like for example Microsoft Excel. Proprietary software tools are not requested as traceability, interdepartmental implementations (e.g. use in the procurement and logistics department), daily use as well as company-specific adaptations and changes would be complicated. Another key requirement is a top-down model for the TCO tool. It should be possible to fill in costs blocks as a whole (black box approach), but if there is a need or the request it should be possible as well to conduct a detailed calculation (opening the black box, detail data, bottom-up approach).

\section{Design of the TCO Tool}

According to the requirements described in chapter 4, the TCO model is designed following a top-down (black box) approach with different key modules. The key modules can be further analyzed in order to fill in base data (bottom-up approach). The key modules of the TCO tool are:

- a macroeconomic analysis module,

- a microeconomic analysis module consisting of:

- a contract price module (purchasing price of the procurement object),

- a strategic procurement module,

- $\quad$ an operative procurement module,

- a transport and logistics module,

- $\quad$ an usage of the procurement object module,

- And a summary module.

The "macroeconomic analysis" module includes all factors and criteria relevant from a macroeconomic perspective. For the procurement decision macroeconomic criteria like oil price, tax rates, inflation, exchange rates or labor costs in a specific country can be of big importance for the customer. An oil price increase or decrease for example will have a direct influence on the transport costs, especially if the distance between the supplier location and the customer's warehouse is long. Secondary effects of an oil price increase may result in longer lead-times for container lines as container ships could reduce travel speed in order to save fuel. In most instances the data set used within this module is comparable to the country assessment module described in chapter 2. A regular update of this data set is required (e.g. every 6 months) as these macroeconomic aspects are normally not in scope of the daily business within the logistics or procurement department.

The module "contract price" (price for the procurement object based on the contract) consists of different sub-elements which are mainly well-known in industrial practice as these elements are often part of the negotiation with the supplier or during the request for quotation (RFQ) [15]. The contract price can be breached down into 
further elements like material costs (e.g. material weight percentage of different metals components in an alloy and their prices), production costs (e.g. costs for different production process steps like turning, milling, welding or polishing), taxes, packaging and so on. Within the TCO tool there is the option to fill in these details in order to use this information for further negotiations with the supplier or to define a contract price as a general input (e.g. contract price per procurement object $=167.80 €$ ).

The module "strategic procurement" includes all issues related to the strategic procurement process in a holistic sense, see figure 1 . These can be for example processes or costs related to the supplier audit (qualification), the supplier development (e.g. costs associated to jointly setting up a production process, know-how transfer from the customer to the supplier in order to improve the production for the required procurement objects), travel costs for integrating a specific supplier or the support for the ramp-up, contracting or specific investments.

The module "operative procurement" includes all issues related to the operative procurement process following the strategic procurement, see [16, 17]. Processes which have to be analyzed within this module are for example the order processing, order monitoring, stock receipt, product qualification and invoicing.

The module "transport / logistics" includes all issues related to the transport of the procurement object from the supplier's location to the customers reception point (e.g. to the warehouse or the construction site for the plant industry). Beside transport costs (e.g. costs for transporting a container from the supplier to the customer's reception point) legal costs, insurance costs and custom duties, certificate of inspections costs may occur. The module "transport / logistics" has a strong dependency with the macroeconomic module (e.g. oil price, taxes or custom duties). In order to limit the data input from a user's perspective, relevant data from the macroeconomic analysis module will be linked to the calculations in this module as far as faultless relationships can be established.

The module "usage of the material" includes issues related to the use of the material, but as described above operating costs, maintenance costs or recycling costs of the procurement object are not included. Especially for plant equipment manufacturers different supply options (suppliers) may require different adaptations of the material on the construction site. An example could be a module delivered from a supplier using own / different tube interfaces standards. In this case tube adaptors have to be used resulting in additional adaption costs.

The module "summary" gives an overview of the results from the modules described before. This module has a quantitative sub-module where the cost blocks are summarized. Another sub-module is qualitative, e.g. a description of risks of a specific supply option. Supply chain risks can be either gathered within each module described before (e.g. risks like earthquakes or piracy which can have an influence on the lead times) or being covered centrally in the summary module. The tool offers the flexibility to adapt this information gathering process as well as the results presentation (e.g. using a cost structure model commonly used within the company) according to needs of each individual company during the implementation process.

The TCO tool is designed in a manner which allows the single use of some modules. The modules can be considered independently, so that it is also possible to use only parts of the described model. It could be for example useful only to use the module "contract price" for the procurement department in order to analyze the cost 
structure of the supplier, e.g. to be used for negotiation or for discussing production process improvements with the supplier. In a similar way the module "transport / logistics" can be used in order to get detail information about the cost structure of the transport and logistics costs.

\section{Conclusion and Outlook}

The prototype version of the TCO model proves to be a robust general approach which can be adopted to individual company needs (e.g. through activating / turning off specific cost blocks). Existing rough estimations used to get the "total" landed costs (e.g. an addition of $20 \%$ of the contract price to cover all the additional costs) could be replaced with this integral TCO approach and results of much higher quality and reliability could be reached according to first analyses.

Even if first results are promising there is still a need to further investigate the TCO concept. Future research should focus especially on the following issues: the dependency of different cost elements and their calculation (e.g. long lead times and the extent of safety stocks) or influence of macro-economic elements to the cost elements (e.g. exact relation of the oil price and the transport costs for a specific route). Up to now we could only describe these relationships and dependencies coarsely. The TCO tool has to be further validated with more case studies (procurement objects), especially in order to analyze long-term consequences of different international supply options. Another interesting aspect will be the combination of the TCO tool with Life Cycle Assessment (LCA) methods (e.g. CO2 analysis) in order to get a holistic ecological-economical analysis of the supply options.

\section{Acknowledgements}

The authors would like to thank the Swiss Federal Innovation Promotion Agency CTI for their support through project 9864.1 PFES-ES (GlobalTCO) and the industry partners.

\section{References}

1. Alard, R., Oehmen, J., Bremen, P.: Reference Process for Global Sourcing. In: Proceedings of the 2007 IEEE IEEM, 13th IEEE International Conference on Industrial Engineering and Engineering Management, Singapore, pp. 367-371 (December 2-5, 2007)

2. Degraeve, Z., Labro, E., Roodhooft, F.: An evaluation of vendor selection models from a total cost of ownership perspective. European Journal of Operational Research 125, 34-58 (2000)

3. Ellram, L.M.: A Taxonomy of Total Cost of Ownership Models. Journal of Business Logistics 15(1), 171-191 (1994)

4. Ellram, L.M.: Total Cost of Ownership: an analysis approach for purchasing. International Journal of Physical Distribution \& Logistics Management 25(8), 4-23 (1995)

5. Ellram, L.M.: Activity-Based Costing and Total Cost of Ownership: a critical linkage. Journal of Cost Management, 22-30 (winter 1995) 
6. Degraeve, Z., Labro, E., Roodhooft, F.: Constructing a Total Cost of Ownership supplier selection methodology based on Activity-Based Costing and mathematical programming. Accounting and Business Research 35(1), 3-27 (2005)

7. Degraeve, Z., Roodhooft, F., Doveren, B.: The use of total cost of ownership for strategic procurement: a company-wide management information system. Journal of the Operational Research Society 56, 51-59 (2005)

8. Carr, L.P., Ittner, C.D.: Measuring the cost of ownership. Journal of Cost Management, 42-51 (fall 1992)

9. DC-SC-M: Project Design Chain - Supply Chain Management. CTI (Confederation's innovation promotion agency) project (2006-2008), http: / / www . dcscm. ethz . ch

10. GlobalTCO: Project Global Total Cost of Ownership. CTI (Confederation's innovation promotion agency) project (2009-2011), http: / / www . globaltco.ethz . ch

11. Alard, R., Paulsson, G.: Beschaffungsmarktforschung im Zeitalter der Globalisierung. Jahreshauptausgabe 2008 des Maschinenbau - Das Schweizer Industriemagazin, 44-46 (2008)

12. Haberfellner, R., Nagel, P., Becker, M.: Systems Engineering. Orell Füssli, 644 p. (2002)

13. Kaplan, R.S.: Innovation action research: Creating new management theory and practice. Journal of Management Accounting Research (10), 89-118 (1998)

14. Global-production.com: Global-production.com, Inc., business economics consultancy (2009), http: / / www.global-production. com

15. de Boer, L., Labro, E., Morlachi, P.: A review of methods supporting supplier selection. European Journal of Purchasing \& Supply Management 7, 75-89 (2001)

16. Arnold, U.: Beschaffungsmanagement, p. 129. Schäffer-Poeschel, Stuttgart (1997)

17. Luczak, H., Eversheim, W., Rüttgers, M., Stich, V.: Industrielle Logistik, p. 181. Wissenschaftsverlag Mainz in Aachen, Aachen (2000) 